\title{
Teaching Interaction Design on Micro Video Teaching Resources
}

\author{
Peng Zhang ${ }^{a}$, Xiuli Gou ${ }^{b}$ \\ College of Foreign Languages, Bohai University, Jinzhou, 121013, China \\ azhangpeng44444@126.com, ${ }^{\mathrm{b}} 1029915835 @ q q . c o m$
}

Keywords: micro video; teaching resources; interaction design; instructional interaction theory

\begin{abstract}
Interaction is an important principle of instructional design, Interaction design is the basis of the application of micro video resources, scientific and rational teaching interaction design can allow students to actively invest in learning, optimize the learning experience, better complete the meaning of knowledge construction. This paper is guided by instructional interaction theory, according to the hierarchical structure of instructional interaction level tower, scheme of interaction design research of micro video teaching efficiency between the students and the media interface interaction, students interaction, learning resources and the interaction between students and students, students and teachers and other aspects of the instructional interaction, the successful application of the research result in this paper can provide more opportunities for interaction, can realize the operation of students from the interaction and information exchange to the concept of interactive quantitative, qualitative change, give full play to the advantages of micro video teaching resources, improve the efficiency of learning.
\end{abstract}

\section{Introduction}

Interaction is one of two or more than two people in a common exchange of ideas, feelings and ideas, and have a mutual impact on each other. Instructional interaction is a kind of happened between the students and the learning environment of the event, including students and teachers, and the communication between students and students, including the mutual communication and interaction between students and various physical and chemical resources. Teaching interaction is an ideal result of the interaction between students and learning environment, and it is also an important attribute of teaching activities to meet the student's needs. The core of the teaching interaction is the students, the purpose is to change student's behavior in the learning process, through a variety of mutual exchange and interaction, so as to achieve teaching goals. When the reaction of the environment to the students can develop in the direction of the teaching goal, the teaching interaction is effective. Therefore, instructional interaction can change the behavior of students, so that students can gradually approach the teaching objectives. Instructional interaction focuses on the interaction and interaction between students and students. The interaction is an important principle of instructional design, interaction design is the application of micro video resources, scientific and reasonable instructional interaction design can make students actively into learning, optimizing the learning experience, improve learning efficiency, better to complete the construction of the meaning of knowledge.

\section{Teaching Interaction Theory}

The essence of instructional interaction is to construct the correct meaning of learning content in the learning process, and the interaction between the learner and the learning environment. Instructional interaction is a multidimensional phenomenon, including the process of learning materials and effective reading students, including discussion and communication between teachers and students; instructional interaction has a clear purpose, even if it is not organized and spontaneous interaction in teaching also has a clear purpose, which is a key feature of education is different from the general interaction; instructional interaction behavior has certain external observability, can be learned by observing the interaction phenomenon; instructional interaction with subjectivity, interaction is the main body of students subjectivity, all interaction results and students have a direct relationship 
with the intrinsic interaction; teaching can not be ignored. In spite of the fact that most of the interaction phenomena can be observed, however, the degree of input in the interaction process, the degree of interaction with the learning is very difficult to understand accurately through the external observation. And the input and the result is the real purpose of education interaction. Therefore, the evaluation of instructional interaction should pay attention to the significance of the student's learning, and should not stay on the characteristics of the image.

Instructional interaction is divided into layers, from the operation of interaction to the information exchange, and then to the concept of interaction, from the concrete to the abstract, from the lower to the higher level. The advanced instructional interaction is based on the low level instructional interaction. Interaction is the base of information exchange, and information exchange is the basis of the concept of interaction, and the concept of interaction is the highest level of interaction. Information interaction includes the interaction between students and teachers, as well as the interaction between students and students, as well as three forms of interaction between students and learning resources. Media is the platform and the carrier of all instructional interaction, and the interaction characteristics of the media are the basis of all teaching interaction. Instructional interaction level tower describes the relationship between the three levels of instructional interaction and abstraction, as well as three levels of instructional interaction environment, as shown in Fig. 1.

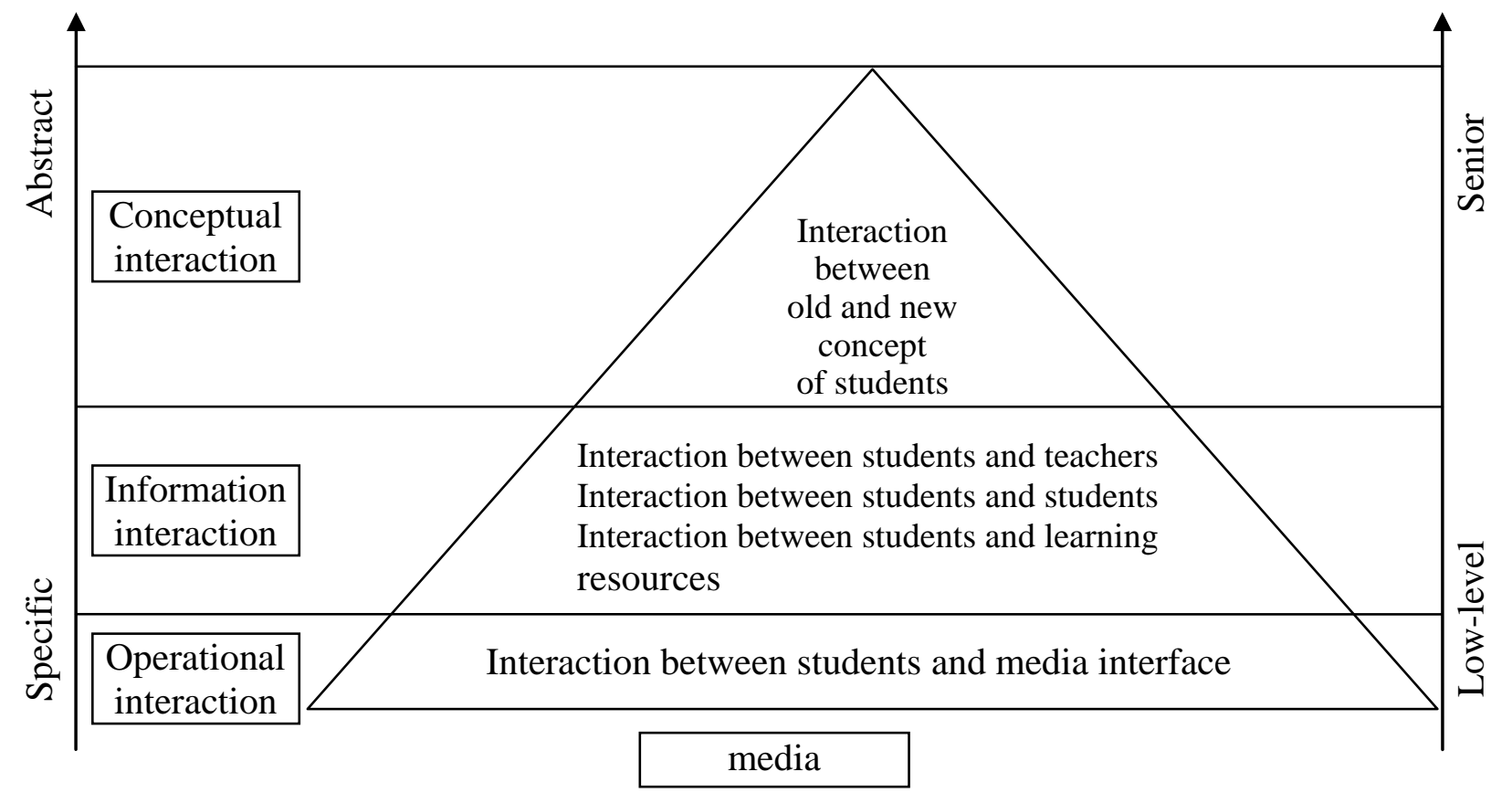

Fig. 1. Teaching interactive level tower

The instructional interaction level tower in the media as the platform, the bottom is the operation interaction; the middle layer is the information interaction, including students and learning resources, the interaction between teachers and students, students and students interaction and interaction of three forms; the top layer is the concept of interaction. In spite of a certain time, three levels of teaching interaction may occur at the same time, but the different levels of teaching interaction is different to the meaning of learning. The higher the level and the more abstract teaching interaction, the key to achieve the goal of learning. According to the teaching interaction level tower, only the concept interaction can produce the true meaning of learning, therefore, information interaction must be aimed at promoting the occurrence of concept interaction. Evaluation of information interaction should be carried out by investigating whether the concept interaction occurs, and whether it is approaching the learning goal orientation. Not only by observing the amount of information interaction information to determine whether the occurrence of learning. 


\section{Interaction Between Students and Media interface}

The operation interaction is a comprehensive reflection of the interaction of the media interface and the proficiency of the student's operation of the media, and also the skill of the learners to use the teaching media. Technology use too much or too complex will become a hindrance to learning. As the level of interaction with the media itself and the complexity of the media and the form of the interface, but also with the students familiar with the media interface. The design flow of media interface is shown in Fig. 2.

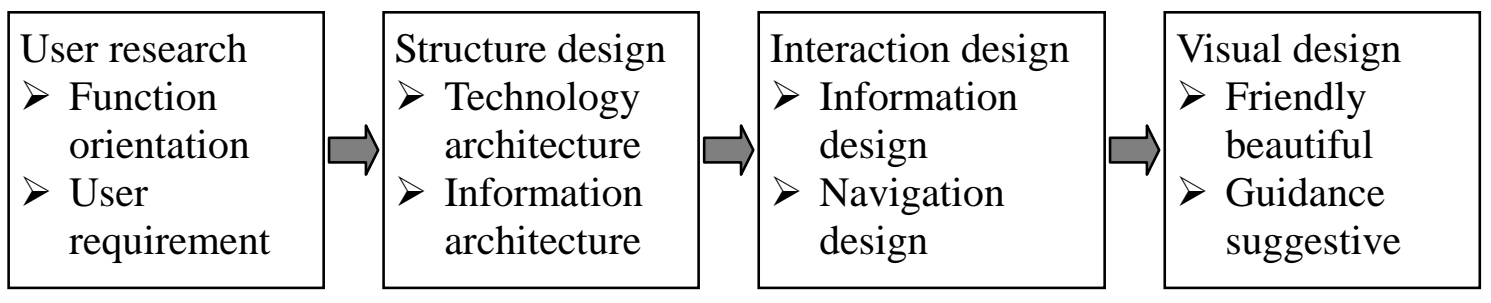

Fig. 2. Design process on media interface

Fig. 2 shows the user interface design process includes four steps: first is the user research. Through the user interface, the user complete a variety of operations, meet the needs of users is the goal of interface design. Therefore, first of all to conduct a systematic research, a clear functional positioning of the interface design and user needs; two is structural design. Based on some design principles, for each part of the system from different angles, collocation and arrangement, a plurality of structure formation system and framework, including the various components, the relationship between components of the externally visible properties and components; Three is interactive design. The purpose is to make the product so that users can simply use. The realization of the function of any product is accomplished through the interaction between human and machine. Therefore, human factors should be reflected as the core of the design; Four is visual design. According to the target group's mental model and task to achieve a plan, including color, font, page, etc.. Visual design to achieve the purpose of user pleasure.

Interactive interface design to follow the Shneiderman of the eight classic rules: as much as possible to maintain consistency. Consistency is the need of people's habits, can not only keep the interface neat and concise, but also can reduce the burden of learning and using the software system. Shortcut keys to improve the operating speed of the system for the frequent use of the system of skilled users, too much interface operation will reduce the use of efficiency; provide a wealth of feedback. Each operation of the user has a corresponding system feedback information in order to enable users to understand the operation of the confirmation; design a complete dialogue process. The dialogue process can be used by the user to clear the current operation, as well as the system is ready to accept or carry out the next step of operation; provide error prevention mechanism. The wrong operation should keep the system in the same state, or the interface should provide a description of the state of the recovery. Users can alleviate the anxiety, because users know that errors can be revoked, which will encourage users to try not familiar with the options to support the internal control trajectory. Users will feel that they have been in control of the system, to encourage users to become active behavior, rather than the behavior of the respondent; reduce the burden of short-term memory. Due to the limitations of short-term memory, it is required to display a simple, multi page display, as well as the frequency of the window moving low.

\section{Interaction Between Students and Learning Resources}

The interaction between students and learning resources is divided into different levels. The interaction is divided into four stages from the low level to the high level: first is the adaptive interaction, the students adapt to the nature of the learning situation, functions and requirements, etc.. Interaction can not be successfully completed, there will be withdrawal, escape and distress and other phenomena. Students must comply with the study situation, gradually increase the degree 
of subjectivity, the new learning situation not to fear, by increasing the time to complete from the strange to the familiar, from the familiar to the skilled and skilled to handle by the psychological change process; two is understanding of the interaction, students in learning activities, reception, information perception understanding and storage, and send feedback information or information exchange. Understanding the interaction including perception, judgment and feedback three links, understanding of the interaction is a specific process, operation is clearly visible, clear point of understanding; three is the operation of the interaction, understanding, mastering and construction of students into two different learning stages tendency. Master, that structural processing and verification of information on the basis of understanding, including the selection, encoding, memorizing, analysis, generalization, migration and application operation. Operation interaction is the core process of a learning generation, the lack of learning will be meaningless; four is reflective interactions, operation is completed does not mean the completion of learning, students also need to learn the results integrated into their own experience and personality, to promote learner personality new the change is to change the learners of this person. Reflective interaction improves the reflective consciousness and reflective skills of the learners, improves the learners' reflective effect and accelerates their own development.

Students and learning resources design should pay attention to the following points: first is the integration of learning resources and curriculum content. Micro video learning resources play a relatively short time, teaching content design must conform to the cognitive planning students, to ensure that the entire video teaching lively and interesting, to ensure learning content rich and complete; the two is arranged widely and changes in practice. The classroom activities to make full use of the characteristics of the classroom knowledge advantage, provides open exercises for learners to cultivate learners' team spirit, innovative spirit and comprehensive ability; three is creating rich resources situation. Micro video resources to text, images and graphics and sound and other resources combined, forming a vivid picture, the learning content is displayed in the situation, can stimulate students' interest in learning, and stimulate students' various senses, to promote students to learn the contents of encoding and retrieval.

\section{Interaction Between Students and Students}

The interaction between students and students is the same as the mechanism of the interaction between teachers and students. Students can not only carry out online discussion activities hosted by teachers, but also should encourage students to communicate in a variety of discussion areas or private chat rooms. Not simply that the interaction between students is only a kind of knowledge exchange activities, it is necessary to establish communication mechanism between students in the network space, namely the establishment of virtual learning community, and discuss the view provides the information sharing platform for students, students can focus on the current study topic discussion, thinking collision the formation of their own judgment, to express their understanding of the problem and solve problems, can also share thoughts with each other, solve all kinds of problems. This interaction can not only broaden student's vision, but also lead students to reflect on various views, cultivate students' divergent thinking. At the same time, promoting the exchange of emotion between learners, mutual appreciation, mutual encouragement, mutual trust and mutual respect, through continuous interaction and development of each other's knowledge and expertise, a mutual influence and mutual promotion of interpersonal relationships form in interactive process.

\section{Interaction Between Students and Teachers}

The interaction between students and teachers including psychological counseling, technical advice, grades, homework, issued a notice, reviews the work, answering questions and discussion interaction etc.. The technology mainly includes the discussion community, e-mail, online answer, correct the homework and share notes etc.. As the guide and help of education, teachers' influence on learning process and learning activities is realized through learning media and learning guidance. Teachers transfer knowledge to students through micro video, which is a way for teachers to act on 
students. When the interaction between the student and the teacher revolves around the curriculum resources and the system, the teachers need to instruct the students directly by issuing the notice of the course or the operation of the learning rules. In the course requirements, it is clear that the main content of the students to learn, learning time, as well as to solve the relevant technical problems. When teaching interactive content on the content of courses, such as course forum, debate and learning activities, teachers need to have the skills to guide students to think, to maintain the students to discuss the order and guide the students to discuss the theme, always pay attention to the trend of the forum, give timely guidance, until the end of the discussion.

\section{Conclusion}

Based on micro video teaching resources, classroom teaching can make the content of the subject taught by the subject to become vivid, image, intuitive, cause the attention of learners to the content of the study, improve the learning enthusiasm of the learners. Traditional classroom teaching materials such as books, textbooks, showing the contents of the study, not only the form of a single and learners are prone to fatigue. English course, English is a language, learning English is used in actual life, listening and speaking, reading and writing all aspects can not be ignored, the use of micro video teaching resources, learners can not only watch the micro video in the classroom, meet the key and difficult points, the class can also be repeated learning conducive to learning and self-improvement. The micro video teaching resources into the traditional classroom teaching, it is not abandoned or abandoned traditional teaching, but in the traditional teaching based on the full use of micro video advantage, so that the integration of both. This has not only played the advantages of multimedia technology, but also improved the quality of classroom teaching. Instructional interaction design is an important aspect of micro video resources. The research results of this paper have important significance for improving the quality of micro video and teaching.

\section{Acknowledgement}

This work is supported by social science fund project of Liaoning province: Construction and application on micro video English teaching resources platform (L14DYY029).

\section{References}

[1] J. T. Chen, M. Wang, J. M. Zhan, D. Kang, "Research on design strategy of micro video teaching content," China CIO News, vol. 28, no. 5, pp. 157-158, 2015.

[2] Jintai Research Network, "Interactive micro video and its application," http://www.jtjyres.com/article/2016/1012/article_20566.html, 2016-10-15.

[3] Q. J. Zhao, X. M. Yang, F. Wang, "Research on Interactive Design of Video Open Course in Universities," Chongqing Higher Education Research, vol. 2, no. 5, pp. 15-21, 2014.

[4] X. D. Wei, "The Application Research on Interactive Theory in Constructing Information Learning Environment," Master's Degree of Hunan Normal University, 2011.

[5] San Lian, "How to design user interface," http://www.3lian.com/edu/2015/08-11/238110.html, 2016-10-11.

[6] X. H. Wei, "Research on Design Development and Practice of Micro-Videos Based on Distance Instructional Interaction Theory," Master's Degree of Guangxi Normal University, 2015.

[7] 360 personal library, "The interaction strategy of learners and learning resources," http://www.360doc.com/content/11/0421/21/6371103_111372163.shtml, 2016-10-11.

[8] X. H. Han, "Four kinds of interaction and interaction in network education," http://www.docin.com/p-960574618.html, 2016-10-20. 
[9] X. Lin, Y. L. Zhou, "On the interactive design of the learning of open curriculum," E-Education Research, vol. 33, no. 2, pp. 84-87, 2012. 